\title{
ANÁLISE DA CONDUTA CIENTÍFICA DO ECONOMISTA, DA ATUALIDADE, NA UTILIZAÇÃO DA TEORIA DA ESCOLHA RACIONAL
}

\section{ARTIGO ORIGINAL}

CARVALHO, Rogério Galvão De ${ }^{1}$

MONTEIRO, Marcel Stanlei ${ }^{2}$

CARVALHO, Rogério Galvão De. MONTEIRO, Marcel Stanlei. Análise da conduta científica do economista, da atualidade, na utilização da Teoria da Escolha Racional. Revista Científica Multidisciplinar Núcleo do Conhecimento. Ano 05, Ed. 11, Vol. 03, pp. 91-106. Novembro de 2020. ISSN: 2448-0959, Link de acesso: https://www.nucleodoconhecimento.com.br/administracao/conduta-cientifica

\section{RESUMO}

A Teoria da Escolha Racional (TER), na primeira metade do século XX, mediante arcabouço técnico-científico muito bem elaborado, sistematizou a hipótese da racionalidade econômica (HRE) e a existência do homo economicus (HE), com a finalidade de normatizar e descrever o comportamento do homem no processo econômico decisório. Essa teoria considera que o $H E$ realiza uma escolha ótima, nesse processo econômico decisório, por intermédio de cálculo matemático de otimização de função. Tal teoria estabelece, que a HRE atenda tanto os aspetos normativos quanto os aspectos descritivos no âmbito científico. Com base na TER, os economistas passam a adotar, nos seus modelos e experiências científicas, a HRE como variável descritiva do comportamento dos agentes econômicos. Esta pesquisa, então pretendeu contribuir para o debate teórico da ciência econômica, a partir de um

\footnotetext{
${ }^{1}$ Mestre Em Economia, Especialista Em Direito Público E Bacharel Em Economia.

2 Orientador. Doutorado em Economia. Mestrado em Economia. Especialização em controladoria e finanças. Graduação em Administração.
} 
problema epistemológico identificado, na produção científica do economista do século XXI. Com a informação de que não se obtém bons resultados nas referidas experiências, e que, ainda assim, o economista, do século XXI, continua adotando a referida hipótese na parte descritiva da produção científica. Corrobora-se, portanto, o problema epistemológico da utilização de uma hipótese refutada, não válida, para a produção científica subsequente. Com isso, para avaliar a conduta desse cientista, com relação ao problema epistemológico identificado, o artigo foi estruturado da seguinte forma: (I) Breve contextualização do problema, na introdução; (II) Discussão teórica, evidenciando a refutação da hipótese e estabelecendo algumas premissas para a conduta dos economistas do século XXI, no marco teórico; (III) Análise do ponto de vista da ética, se esse é um comportamento esperado ou desviado, utilizando para isso a corrente utilitarista; (IV) Seção específica para tratar da epistemologia desenvolvida pelos cientistas da TER, que pode ter contribuído para que as refutações empíricas não consigam atingir a HRE dessa teoria, influenciando sobremaneira para a conduta desviada desses economistas e por fim (VI) a conclusão.

Palavras Chaves: Filosofia Econômica, Teoria Racional da Escolha, Hipótese da Racionalidade Econômica dos Agentes.

\section{INTRODUÇÃO}

A Discussão sobre a existência da racionalidade econômica dos agentes (consumidores, produtores e governo) nos processos econômicos decisórios, isto é, uma escolha racional do ponto de vista da decisão ao comprar, vender, ou produzir bens (ou serviços), ou ainda regular os mercados é uma discussão histórica. Desde o século XVII, os pensadores da ciência econômica discutem esse assunto.

Por exemplo, para Poundstone (2011), nos primórdios a ciência econômica abstraiuse das outras dimensões: morais, religiosas, políticas, culturais etc., para focar suas investigações nas duas funções elementares exercidas por todo e qualquer indivíduo: o consumo e a produção, ignorando completamente qualquer outra parte da vida de seres humanos. O homo economicus, surge como o agente racional, um fragmento 
do ser humano, que produz e consome, segundo "normas" apoiadas nas evidências das observações.

Segundo Albou (1984), as principais correntes filosóficas que são responsáveis pelo conceito da racionalidade econômica são: o hedonismo e o utilitarismo. No hedonismo, o homem se sujeita à lei natural buscando prazer e bem-estar e evitando a dor. No Utilitarismo, a busca é pelo que for útil ou valioso. No século XX, no entanto, a Teoria da Escolha Racional (TER) sistematizou essa discussão e se tornou o mainstream da ciência econômica quando o assunto é esse.

O entendimento dos economistas, adeptos da TER, é que o comportamento dos agentes econômicos para escolher, no processo econômico decisório, passa pela resolução de um problema matemático de otimização de função, com restrições, ou seja, o homo sapiens se transforma no homo economicus e escolhe de forma ótima como proceder naquele momento (de compra, de venda, de produção ou de regulação), calculando matematicamente a escolha ótima.

De acordo com Fernandez e Bèrni (2014) uma crítica recorrente à HRE, diz respeito à blindagem da teoria contra a refutação e outra se refere à inadequação empírica dessa hipótese do ponto de vista epistemológico. Apesar da blindagem, constatada no artigo dos autores, há diversas comprovações empíricas de que, na parte descritiva do comportamento, na maioria das vezes a escolha ótima não acontece, isto é, ao descrever o comportamento humano, utilizando a HRE, no que se refere à escolha do processo econômico decisório, o cientista não teve bons resultados, nos seus experimentos, isto é, a HRE fora comprovadamente refutada por diversas vezes.

Daí a ideia de se questionar o porquê de os economistas continuarem utilizando, nesse caso, a HRE para os agentes, quando se trata, da tentativa de descrever o comportamento dos seres humanos, no que diz respeito a tomada de decisão, quando se trata da escolha econômica ótima. Porque, nesse caso, a TER ainda é tratada como mainstream na produção científica dos economistas? 
Ressalte-se que não se trata da discussão sobre a refutação da hipótese, porque de acordo com as recentes teorias econômicas, ela está refutada, no que diz respeito ao eixo descritivo da ciência, de acordo com elas há tantas limitações, que o modelo não serve, para descrever o comportamento econômico dos seres humanos no dia a dia, sendo ainda bastante útil na parte normativa para a produção da ciência econômica.

Saliento ainda que apesar de tecnicamente as modelagens, (especialmente no ramo da economia), partirem de hipóteses relativamente falsas, adotarem testes estatísticos bastantes contundentes (para a validação das premissas) e cotejarem os resultados com a realidade.

Os resultados no caso da HRE, na tentativa de descreverem ou explicarem o comportamento real do homem, não foram promissores, não funcionaram, não se confirmaram com o que realmente aconteceu, deixando claro que o homo economicus da HRE, pode ser relevante apenas no âmbito normativo da ciência econômica.

Esse artigo tenta contribuir com o debate da seguinte forma: (1) evidenciando a refutação da hipótese e estabelecendo algumas premissas para a conduta dos economistas do século XXI; (2) analisando do ponto de vista da ética, se esse é um comportamento esperado ou desviado, utilizando para isso a corrente utilitarista; e (3) fundamentando uma das hipóteses prováveis para essa conduta, com a análise da epistemologia própria criada pela TER.

\section{MARCO TEÓRICO}

Segundo Thaler (2019), A Teoria da Escolha Racional - TER, contém um sólido e robusto arcabouço lógico-matemático, onde se define que os agentes econômicos são racionais e cada um resolve um problema de maximização de função, sujeito a restrições, para obter a escolha ótima num processo econômico de tomada de decisão. Ela assume que as decisões econômicas são tomadas com base exclusivamente em aspectos econômicos da personalidade, surge o homo economicus, em detrimento do homo sapiens. 
Para Fernandez e Bèrni, (2014), no que diz respeito à HRE, são oito os aspectos mais relevantes na escolha dos agentes: (1) Estrutura determinada e ordenada de preferências; (2) Elas são completas e transitórias; (03) São exógenas e permanecem inalteradas durante o processo de troca; (04) As preferências de cada agente econômico são independentes e incomparáveis entre si; (05) Os agentes atribuem diferentes utilidades aos resultados possíveis das suas ações; (06) Também atribuem probabilidades aos resultados esperados; (07) Eles atuam fundamentalmente movidos pelo interesse próprio; e (08) O resultado é a média das utilidades ponderadas pelas probabilidades de ocorrência dos diferentes estados, a sua utilidade esperada, que se esforçam por maximizar.

Mas no que tange ao aspecto científico descritivo, da HRE, ou seja, do comportamento do ser humano no processo decisório, para a escolha ótima, é reconhecida a fragilidade, em várias teorias econômicas posteriores, em particular a Teoria da Decisão, Simon (1976); e a Teoria do Prospecto, Kahneman e Tversky (1974) e finalmente a crítica de Green e Shapiro (1994) que chama a atenção para a parte descritiva da HRE instituída pela TER, com os resultados ruins dos modelos empíricos.

Estes autores têm uma ideia totalmente contrária às ideias postuladas sobre o homo economicus, que é o ser que simbolicamente toma todas as decisões baseadas exclusivamente nos aspectos econômicos, criando expectativas racionais para os agentes econômicos. De acordo com esses pensadores, quando se trata da parte descritiva da produção científica, a HRE, não é uma boa opção, ou seja, tal hipótese não descreve nem explica o real comportamento dos seres humanos quando o assunto é o processo econômico decisório.

De acordo com Simon (1978), o processo de tomada de decisão envolve três fases (1) a prospecção, que consiste em determinar as estratégias possíveis no econômico processo decisório; (2) a concepção que trata de determinar as consequências possíveis da escolha; (3) a decisão propriamente dita, isto é, a escolha da melhor alternativa dentre as possíveis. 
Nesse contexto, o autor enfatiza a impossibilidade de o agente econômico, conhecer todas as alternativas e inferir as respectivas consequências durante o processo econômico decisório e assim otimizar a escolha. Dessa forma, estabelece a possibilidade estocástica da escolha e não determinística, como pretendia os adeptos da TER.

De certo modo, Sem (1999) com base no utilitarismo, não concorda com reduzir os critérios de utilidade a um único elemento, apesar de facilitar o cálculo de utilidade, o custo é o de perder a própria justiça buscada. Ele critica as concepções reducionistas que normalmente estão intrínsecas do pensamento econômico.

De acordo com Kahneman e Tversky (1974), ao analisarem o comportamento em relação ao risco, para agentes no processo econômico decisório perceberam escolhas diferentes, ocorre aversão quando se trata de ganhos, mas quando se trata da possibilidade de perda, este indivíduo tende a ser propenso ao risco. Portanto, de um lado os agentes são avessos ao risco para ganhos e por outro, eles são propensos ao risco para as perdas. O que de fato, corrobora a refutação da HRE, para descrever ou explicar o comportamento do ser humano de escolha ótima em processos econômicos decisórios.

Também com relação a troca de preferências no transcurso de processos econômicos decisórios, segundo Kahneman e Tversky (1979), foram identificados alguns efeitos, denominados por eles de: (1) efeito certeza, os indivíduos compararam as possibilidades de um evento certo a um evento provável e escolheram o evento certo, mesmo que o evento provável seja melhor. (2) efeito reflexo, (aversão ao risco quando se trata de ganhos e propensão ao risco no campo das perdas) as pessoas buscaram ganhos seguros e perdas arriscadas. (3) o efeito isolamento agentes que apresentaram dificuldades em reconhecer seus erros.

Para Green e Shapiro (1994) o grande problema centra-se no fato de que TER não cumpre seu papel. A raiz do desequilíbrio entre a construção da teoria e o trabalho empírico está na ambição científica da escolha racional de chegar a uma teoria universal, apesar de um histórico empírico decepcionante. De acordo com eles, a 
reivindicação da universalidade científica é ecoada e reforçada pela forma como a TER tem sido conduzida, quando se permite que o trabalho teórico tenha maior reconhecimento do que os estudos empíricos. Esta situação criou um efeito de incentivo no qual os estudiosos da escolha racional concentram seus esforços na elaboração de teorias e prestando pouca atenção à forma como essas teorias poderiam ser operacionalizadas e testadas.

Esta dicotomia, ainda segundo os autores, é motivo de alarme porque a busca de explicações teóricas deduzidas de modelos de equilíbrio geral levou a um padrão de inadequações explicativas: as hipóteses são formuladas de maneiras inerentemente resistentes a testes empíricos genuínos, e com isso: (1) não há atenção às explicações concorrentes; (2) os argumentos dedutivos são alterados em aperfeiçoamentos posteriores para contornar os resultados, os fatos concretos. Estas patologias são perigosas porque ameaçam a validade científica da TER.

Os trabalhos empíricos que se seguiram ao longo dos anos, após a consolidação da TER, como mainstream da ciência econômica, Tversky e Kahneman (1981), Dosi e Egidi (1991) e Kreps (1990) demostram que não há dúvida de que a HRE dos agentes (homo economicus) é tão restritiva que não pode ser considerada como um pressuposto válido para os avanços nesta área do conhecimento, no que diz respeito ao seu aspecto descritivo da ciência, ou seja, para descrever o comportamento econômico do homem nos processos decisórios, se valendo de cálculos matemáticos para definir uma escolha ótima.

De acordo com os autores, ainda que os modelos sejam relevantes para a ciência, partam de uma hipótese falsa, pois elege apenas algumas variáveis, para tentar descrever, ou explicar a variável problema (explicada), a HRE do agente não deve ser utilizada, porque fora comprovadamente refutada.

No Brasil, por exemplo, de acordo com o Inquérito Nacional sobre Dívida das Famílias e Deficiência do Consumidor, conduzido pela Confederação Nacional do Comércio de Bens, Serviços e Turismo (CNC), a porcentagem de famílias com dívidas de cartão de crédito, cheques especiais, cheques pré-datados, créditos consignados, créditos 
pessoais, cartões de loja, pagamentos de automóveis e pagamentos domésticos em Dezembro de 2019 era de 65,6\% (sessenta e cinco vírgula seis por cento).

Com o exemplo anterior, fica claro, que (no cotidiano), não existe o homo economicus, a maioria dos consumidores, no que tange à resolução do problema de maximização da utilidade do consumo restrito a renda do referido consumidor, erra sua escolha ótima.

Ainda assim, conforme Foley (2003) a maioria dos economistas do século XXI, ainda utilizam os preceitos da TER, no que tange a HRE dos agentes, em processos decisórios, para tentar descrever o comportamento dos agentes econômicos, quando produzem conhecimento científico ao elaborar seus modelos, recursivamente aprimorados, buscando cada vez mais especifica-los (incluindo ou retirando variáveis).

Esse cientista, o economista do século XXI, de acordo com o autor, acredita que na média o homem, se transforma numa espécie de robô, e age com base na resolução de um problema matemático de otimização de função com restrição, para realizar a escolha econômica ótima. Surge então, a crença de que se os fatos não corroboram a TER, isto se deve ao fato de o proposto modelo necessitar de reformulação, para ser mais bem especificado, e se adequar a realidade.

Um dos preceitos da epistemologia para que a produção de conhecimento seja considerada científica (e se perpetue como ciência) é que diante de uma hipótese refutada, portanto de validade nula, espera-se duas atitudes: (1) que não se utilize tal hipótese como fundamento da produção científica subsequente; e (2) que se ocupe da substituição dessa hipótese, não válida. Com este visível problema epistemológico, a ideia é tentar entender o motivo pelo qual estes economistas ainda tratam a TER como mainstream da ciência econômica, com isso apontamos algumas hipóteses prováveis para esse comportamento científico, que se percebe são: (1) A reputação científica, acadêmica e técnica do economista; (2) A crença de que a TER não foi refutada; e (3) a formulação de uma epistemologia própria pela TER. Por isso, avaliaremos nas próximas seções a conduta do economista. Essa avaliação, do ponto 
de vista da corrente de pensamento utilitarista da ética, consiste em definir se tal conduta é uma conduta esperada ou um desvio de conduta.

Além disso, no último tópico desse trabalho há uma análise sobre a epistemologia específica desenvolvida pela escola de Chicago, sobre a TER, que talvez seja o ponto chave da discussão filosófica do motivo pelo qual a TER ainda é considerada, pelos economistas contemporâneos, como mainstream dessa ciência.

\section{ANÁLISE DA ÉTICA UTILITARISTA}

Segundo Leclercq (1967), existem três tipos de pensamento que estão relacionados com a moralidade: (1) pensamento normativo, como o de Sócrates que se pergunta o que é certo ou bom; (2) pensamento analítico, crítico ou meta-ético, que consiste na resposta das questões lógicas, epistemológicas ou semânticas; e (3) pensamento que se concentra na investigação empírica e descritiva, histórica ou científica, cujo objetivo é descrever ou explicar fenômenos morais ou construir uma teoria da natureza humana que se refere a questões éticas. Este é o tipo desenvolvido por John Stuart Mill.

O Utilitarismo apresenta a ação útil como a ação correta. O termo, segundo Vasquez (1993), foi utilizado pela primeira vez na carta de Jeremy Bentham para George Wilson em 1781 e posto em uso corrente na filosofia por John Stuart Mill na obra Utilitarismo, de 1861, o termo "utilitarismo" se refere à teoria defendida por Bentham e Mill, a maximização da promoção da felicidade.

Na doutrina utilitarista de Jeremy Bentham e John Stuart Mill, prevalece o princípio do máximo bem-estar, isto é, o comportamento esperado, neste caso concreto, do cientista econômico, deve ser o de extrair o máximo de benefício da sua ação, ao produzir ciência. $O$ conceito mais amplo de utilitarismo prioriza as regras ao invés das ações morais individuais.

A utilidade, de acordo com Baumer (1977), significava uma preocupação com o bemestar geral, associada a uma felicidade dos seres humanos, tanto individualmente 
quanto coletiva, que só se poderia atingir experimentalmente. A utilidade, então, se dava com base nos fatos selecionados pela experiência.

Assim, no que diz respeito à produção científica, de acordo com os preceitos desta corrente de pensamento, para esse dilema ético, podemos inferir que a conduta esperada do economista do século XXI (ao produzir ciência), seria exatamente o que preconiza a epistemologia para preservar o conhecimento científico como tal, isto é, a: (1) a de não utilizar a hipótese refutada como se fosse válida; (2) a de se ocupar de substituir a hipótese nula por outra válida.

Se a conduta esperada do cientista não é utilizar uma hipótese refutada, como se fosse válida, para elaborar seus modelos teóricos ou empíricos. Então, nesse caso, esses economistas têm um desvio de conduta ético, porque o melhor para a ciência econômica, no que diz respeito a sua sobrevivência como ciência, é respeitar os preceitos da epistemologia filosófica.

\section{EPISTEMOLOGIA DA TEORIA DA ESCOLHA RACIONAL}

De acordo com Fernandez e Bèrni, (2014) a hipótese de racionalidade econômica consiste na existência do homo economicus é implantada em 08 (oito) hipóteses básicas sobre o comportamento dos agentes nas suas interações, que estruturarão a concepção de comportamento racional, segundo a TER.

Podem ser simplificados da seguinte forma: (1) os agentes têm uma estrutura determinada e ordenada de preferências (que representam os seus desejos); (2) as preferências são completas (o agente prefere um bem a outro ou vice-versa ou continua indiferente entre as mercadorias) e transitórias (se o agente, em frente de três mercadorias, prefere um bem a outro e este ao terceiro bem, então ele preferirá necessariamente o primeiro ao terceiro bem); (03) as preferências são exógenas (formadas fora do âmbito da modelização) e permanecem inalteradas durante o processo de troca; (04) as preferências de cada agente econômico são independentes e incomparáveis com as de outros agentes; (05) os agentes atribuem diferentes utilidades aos resultados possíveis das suas ações, (06) os agentes atribuem 
probabilidades à realização dos resultados esperados, às quais foram atribuídas utilidades; (07) os indivíduos atuam fundamentalmente movidos pelo interesse próprio: Atuam com o objetivo de satisfazer os seus interesses pessoais, sem ter em conta outros aspectos considerados irrelevantes no processo; (08) como as crenças do agente são abaladas pela incerteza quanto à obtenção de resultados específicos, a sua tomada de decisão considerará a média das utilidades fornecidas pelas ações adoptadas em resposta às probabilidades de ocorrência dos diferentes estados, a sua utilidade esperada, que se esforçam por maximizar.

Segundo Karl Popper em Fernandez e Bèrni, (2014), estas hipóteses são irrefutáveis, sobretudo porque não se situam no plano lógico-teórico. A irrefutabilidade do princípio da racionalidade resultaria do fato de estar situado num plano lógico "superior" ao plano teórico, o plano metodológico (ou meta-teórico).

Com a estrutura cognitiva da irrefutabilidade desta hipótese, os postuladores da TER, criaram a sua própria epistemologia, uma espécie de escudo, onde experiências empíricas e observações de dados na vida real não podem, precisamente por estarem situadas num plano inferior, contradizer a hipótese da racionalidade econômica dos agentes, isto quer dizer que a premissa do homo economicus, tem um status diferenciado, ou seja, não pode ser considerado, nem um axioma, nem uma lei, nem uma hipótese empírica da teoria, de acordo com os autores.

Fortalecendo o pensamento de Green e Shapiro (1994) sobre o efeito de incentivo no qual os estudiosos da escolha racional concentram seus esforços na elaboração de teorias e prestando pouca atenção à forma como essas teorias poderiam ser operacionalizadas e testadas.

Daí, com base nessas considerações, acerca da TER e da sua epistemologia diferenciada, pode-se inferir, com auxílio de Tribe (1997) e Karl Popper em Fernandez e Bèrni, (2014), que há uma dificuldade, por parte dos economistas do século XXI, de se aceitar a refutação da hipótese, ainda que os dados empíricos demonstrem o contrário. 


\section{CONCLUSÃO}

Este trabalho baseou-se nas recentes discussões sobre a racionalidade econômica dos agentes, no que diz respeito, a escolha ótima, quando se trata do processo econômico decisório. O problema discutido foi a produção científica dos economistas do século XXI, com base numa hipótese refutada, no contexto descritivo de formulação da ciência econômica, quando se trata desse assunto.

Em primeiro lugar, fora contextualizado o problema identificado, na primeira seção e sistematizado, na seção seguinte, um referencial teórico para corroborar a refutação da HRE dos agentes (consumidores, empresários e governo), ou seja, a existência do homo economicus quando se trata das decisões reais, do cotidiano.

É importante ressaltar que os modelos empíricos, com base nessa hipótese, elaborados pelos economistas, para descrever a escolha dos agentes, num processo econômico decisório, não tiveram bons resultados ao tentar descrever a escolha dos seres humanos. Apesar da refutação comprovada no aspecto descritivo, de produção científica, por outro lado, a hipótese ainda continua válida para as questões normativas da ciência econômica.

Depois se discutiu (do ponto de vista da corrente utilitarista do pensamento ético) com a intenção de avaliar a conduta do cientista econômico do século XXI, se tal comportamento é uma conduta esperada ou se é um desvio de conduta. Segundo essa corrente, concluiu-se que a atitude (na produção científica) dos economistas é um desvio de conduta do ponto de vista ética utilitarista.

No transcurso da análise da questão ética do comportamento do cientista econômico, observou-se que talvez o problema não seja tanto a conduta ética desviada dos referidos economistas. O maior problema revelado (como podemos observar na última seção) seria a epistemologia diferenciada da TER, que protege de forma contundente a construção desse arcabouço científico. 
Nesta última seção, de acordo com os autores citados, fica assinalada a existência de irrefutabilidade da HRE dos agentes, por conta dessa premissa elaborada num nível quase meta-teórico, obscurecendo, segundo os autores que trataram do assunto, o entendimento (sobre este ponto) e as atitudes dos investigadores econômicos.

Assim, a organização teórica da HRE dos agentes (revelando a existência suprema do homo economicus) em torno da TER, cuja epistemologia diferenciada, não permite a refutação, por evidências empíricas, pode ter sido uma forte razão pela qual os economistas ainda utilizam esta hipótese, como se fosse válida, na produção científica de modelos econômicos, no que diz respeito à parte descritiva das ações humanas em relação à escolha nos processos decisórios da economia. Demonstrando a crença de que, ao menos para eles, a HRE dos agentes, não pode ser refutada, o que se pode fazer é, cada vez mais, especificar melhor os modelos para que consigam calcular com maior precisão a maximização do problema da escolha ótima.

\section{REFERÊNCIAS}

ALBOU P. (1984) La psychologie économique, Paris, PUF.

BAUMER, F. L. (1977) O pensamento europeu moderno. v.I,II (Séculos XVII, XIII, XIX e XX). 7 a ed. Rio de Janeiro.

BENTHAM, J. (1979) Os pensadores. São Paulo: Abril Cultural.

CANO, W. (2002) Ensaios sobre a formação econômica regional do Brasil. Campinas: Unicamp.

FEIJÓ, R. (2001) História do Pensamento Econômico. Editora Atlas.

FERNANDEZ, B.P.M. E BÈRNI, D. A. (2014) Sobre o estatuto epistemológico da racionalidade econômica segundo Karl Popper. Estudos Econômicos vol.44 ํo.4 São Paulo. 
FOLEY D. K. (2003) Rationality and Ideology in Economics. lecture in the World Political Economy course at the Graduate Faculty of New School UM, New School.

GREEN, D.; SHAPIRO, I. (1994) Pathologies of rational choice theory. New Haven: Yale University Press.

HUNT, E. K. (2005) História do Pensamento Econômico. Editora Campus.

LECLERCQ, J. (1967). As grandes linhas da filosofia moral. São Paulo: Ed. Herder; Ed. da USP, 1967.

MILL, J. S. (2000). O utilitarismo. São Paulo: lluminuras. Tradução de: The utilitarism.

PEREIRA, R. S. (2011) Alguns pontos de aproximação entre a ética aristotélica e a kantiana, Transformação vol.34 no.3 Marília, São Paulo.

POUNDSTONE, W. (2011). Priceless: The Hidden Psychology of Value, London: Oneworld Publications.

SHAPIRO, I.; Green, D. (1994) Pathologies of rational choice theory: a critique of applications in Political Science. New Haven: Yale University Press.

SEN, A. (1999). Sobre ética e economia. São Paulo: Companhia das Letras

SEN, A. (2017). Collective choice and social welfare. Cambridge, Mass.: Harvard University Press.

SIMON, H.A. (1955) A behavioral model of rational choice. The Quarterly Journal of Economics, volume 69, number 1, p. 99-118.

SIMON, H.A. , (1959) Theories of decision-making in economics and behavioral science. The American Economic Review, volume 49, number 3, p. 253-283.

SIMON, H.A. (1978) Rationality as process of and as product of thought. American Economic Review, volume 68, number 2, , p. 1-16. 
SIMON, H.A. (1980) A racionalidade do processo decisório em empresas. Multiplic, volume 1, número 1.

THALER, R.H.(1980) Toward a positive Theory of Demand. Economic journal 105, no 433: $1519-23$.

TRIBE, K. (1997) Economic Careers. Economics and economists in Britain 1930-1970. ed. Routledge.

THALER, R.H.(1986) The Psychology and Economics Conference Handbook: comments on Simon, on Einhorm and Hogarth, and on Tversky and Kahneman. Journal of Business 59, no 4, parte 2: S279-84.

THALER, R.H.(2019) Misbehaving The Making of Behavioral Economics, (tradução George Schleinger) 1를 Ed Rio de Janeiro, Ed. Intrínseca.

VASQUEZ, A. S.(1993) Ética. 14. ed. Rio de Janeiro: Civilização Brasileira, 1993.

Enviado: Outubro, 2020.

Aprovado: Novembro, 2020. 